\title{
Direct Oral Anticoagulants for the Treatment of Venous Thromboembolism in Patients With Active Cancer
}

\author{
MISATO OGATA ${ }^{1}$, YUMI AMA ${ }^{2}$, TAKATSUGU OGATA ${ }^{1}$, \\ MASAKI HIRABATAKE ${ }^{2}$, HISATERU YASUI ${ }^{1}$ and HIRONAGA SATAKE ${ }^{1,3}$ \\ ${ }^{I}$ Department of Medical Oncology, Kobe City Medical Center General Hospital, Kobe, Japan; \\ ${ }^{2}$ Department of Pharmacy, Kobe City Medical Center General Hospital, Kobe, Japan; \\ ${ }^{3}$ Cancer Treatment Center, Kansai Medical University Hospital, Osaka, Japan
}

\begin{abstract}
Background/Aim: Although direct oral anticoagulants (DOACs) are as safe and effective as conventional anticoagulants for treating venous thromboembolism (VTE), we have insufficient evidence justifying their use in patients with active cancer. We investigated the safety and effectiveness of DOACs in patients with active cancer. Patients and Methods: To investigate the safety and efficacy of DOACs, we retrospectively extracted 312 consecutive patients with active cancer who were prescribed edoxaban, rivaroxaban or apixaban for VTE. Results: The most common primary cancer sites were the lung, stomach, colon/rectum, hematology, ovary, and pancreas. Fifty patients (16\%) discontinued DOACs due to clinically relevant bleeding; major bleeding events occurred in 18 patients (5.4\%). Thrombosis reduced or resolved in 144 of 167 evaluable patients (86\%). In particular, pulmonary embolism was reduced or resolved in 46 of 50 patients (92\%). Conclusion: Our findings revealed that DOACs for cancerassociated VTE are as safe and effective as conventional anticoagulation therapy.
\end{abstract}

Patients with cancer are at an increased risk of venous thromboembolism (VTE), even in the absence of conventional VTE risk factors (1). Patients with cancer account for $20 \%$ of patients with VTE, and experience VTE at a rate 4-8 times higher than that of the general population $(2,3)$. In Japan, among the known risk factors for VTE, a

This article is freely accessible online.

Correspondence to: Hironaga Satake, Cancer Treatment Center, Kansai Medical University Hospital, Osaka, 2-3-1 Shinmachi, Hirakata City, 573-1191, Japan. Tel: +81 729040101, e-mail: takeh1977@gmail.com

Key Words: Direct oral anticoagulants, DOACs, cancer associated thrombosis, CAT, cancer, venous thromboembolism, pulmonary embolism. medical history of cancer was found to be the most prevalent, with $27 \%$ of patients with VTE having such a history, according to the Japan VTE Treatment Registry (JAVA) study (4). Furthermore, a prospective follow-up study, which measured the 12-month cumulative incidence of recurrent VTE in individuals with and without cancer, showed a hazard ratio of 3.2 for recurrence in patients with cancer (4). Although the molecular basis of this relationship between cancer and VTE remains unclear, the long-term use of effective anticoagulants need to be implemented regardless of the underlying mechanisms. However, patients with cancer and VTE have a $12.4 \%$ risk of bleeding per year during anticoagulant therapy, and they have a higher risk of bleeding than non-cancer patients (5). Additionally, VTE itself may be directly responsible for mortality in patients with cancer. Among non-cancer-related causes of death, thrombosis was the leading cause (9.2\%) (6). Only $12 \%$ of patients in whom cancer was diagnosed at the time of an episode of primary VTE were alive after 1 year, compared to the survival rate of $36 \%$ for patients who did not have cancer $(p<0.001)(7)$.

Direct oral anticoagulants (DOACs) include factor IIa inhibitor (dabigatran) and factor Xa inhibitors (edoxaban, rivaroxaban, and apixaban). Among them, edoxaban, rivaroxaban, and apixaban have been approved for treating VTE as well as atrial fibrillation.

According to existing therapeutic guidelines, lowmolecular-weight heparin (LMWH) is widely recommended for treating patients with cancer who have VTE (8-10). The American Society of Clinical Oncology Clinical Practice Guideline was updated recently and administering DOACs has become the recommended treatment strategy for initial as well as for long-term anticoagulation therapy, which is a remarkable change. However, three DOACs have been recommended with different guidelines; rivaroxaban is recommended for both initial anticoagulation and long-term anticoagulation, edoxaban for long-term anticoagulation and apixaban is not mentioned. It should be investigated whether 
these three DOACs can be used equally or whether they should be used differently depending on the type of anticoagulation therapy. In fact, LMWH is not covered by medical insurance for treatment for VTE in Japan; the standard anticoagulant therapy for patients with VTE is continuous intravenous administration of unfractionated heparin (UFH), followed by oral administration of vitamin $\mathrm{K}$ antagonists (VKA), warfarin. For VTE treatment with UFH, the activated partial thromboplastin time needs to be measured every $6 \mathrm{~h}$ after administering the drug. Warfarin, VKA, requires monitoring the prothrombin timeinternational normalized ratio (PT-INR), and its interactions with other drugs such as fluorouracil anticancer drugs are often problematic. This suggests that treatment with UFH and warfarin requires more supervision and monitoring than that with DOACs.

DOACs are reportedly as safe and effective as conventional anticoagulants (heparin followed by vitamin $\mathrm{K}$ antagonists) for treating $\operatorname{VTE}(10,11)$. DOACs do not require monitoring like UFH or VKA and they have little interaction with other drugs. For these reasons, use of DOACs for patients with cancer is of great interest, and DOACs have often been employed to treat patients with active cancer in clinical practice. Although several clinical trials on the use of DOACs for cancer-associated VTE have been published recently with promising results $(12,13)$, evidence for the use of DOACs in patients with cancer is still limited. Therefore, in the present study, we assessed the safety and effectiveness of DOACs for treatment of VTE in patients with active cancer. To the best of our knowledge, this is the first study to show actual experience of managing VTE in patients with cancer using edoxaban, rivaroxaban, and apixaban.

\section{Patients and Methods}

Patients. We retrospectively collected data from the electronic medical records of patients prescribed both intravenous anticancer drugs and DOACs, namely edoxaban, rivaroxaban, or apixaban, from July 2011 to December 2018 at the Kobe City Medical Center General Hospital. The Institutional Review Board approved this study, and since this was a retrospective investigation, the requirement to obtain informed consent was waived. A patient with active cancer was defined as a patient who had been diagnosed with cancer either at baseline or during the study. The indication for DOACs was VTE (deep vein thrombosis, DVT, and/or pulmonary embolism, PE) or atrial fibrillation. Patients who did not receive intravenous anticancer therapy, who were prescribed DOACs for reasons other than VTE, and whose cancers were not active were excluded.

Outcome assessments. The primary outcome was the rate of clinically relevant bleeding events while receiving DOACs. The secondary outcomes were reasons for drug discontinuation, the relationship between renal function and the bleeding event, and the resolution or improvement rate of the VTE and D-dimer levels.
Bleeding was defined as major if it was associated with the need for a blood transfusion ( $\geq 2$ units of blood), as defined by the International Society on Thrombosis and Hemostasis (14). Adverse events were recorded during the administration of drugs, including bleeding related to DOACs. Resolution and improvement of the thrombus were evaluated using images obtained via vascular ultrasonography and/or computed tomography.

Statistical analysis. Differences in renal function between patients with and without bleeding and the 1-month changes in the D-dimer levels were evaluated using the Student's $t$-tests. Differences in the bleeding rates according to the renal function were evaluated using the chi-squared test. All statistical analyses were performed using SPSS 22.0 (IBM Corp., Armonk, NY, USA). All statistical tests were two-tailed, and differences were considered statistically significant if $p<0.05$.

Ethics approval and consent to participate. This study was carried out in accordance with the Helsinki Declaration and Ethical Guidelines for Clinical Studies and was approved by the institutional review boards of all three participating hospitals, Kobe City Medical Center General Hospital (The reference number, zn190509).

\section{Results}

Patients. From July 2011 to December 2018, 312 consecutive patients received edoxaban, rivaroxaban, or apixaban and were included in this study. Specifically, 205 patients received edoxaban, 74 received rivaroxaban, 33 received apixaban, and 14 patients received two or more DOACs during the study period.

The characteristics of these patients at the initiation of DOACs are summarized in Table I. The median age of enrolled patients was 68 years (edoxaban, 69 years; rivaroxaban, 63 years; apixaban, 68 years), 137 patients were men $(44 \%)$, and the mean creatinine clearance rate (Ccr) was $79.9 \mathrm{ml} / \mathrm{min}$ (edoxaban, $78.9 \mathrm{ml} / \mathrm{min}$; rivaroxaban, 86.5 $\mathrm{ml} / \mathrm{min}$; apixaban, $70.8 \mathrm{ml} / \mathrm{min}$ ). The apixaban group had significantly lower renal function than the rivaroxaban group $(p=0.02)$. The primary sites of cancer were the lungs $(\mathrm{n}=63$, $20 \%)$, stomach $(n=42,13 \%)$, colon/rectum $(n=38,12 \%)$, ovary $(n=33,11 \%)$, and pancreas $(n=14,4 \%)$.

In the edoxaban group, $23 \%$ of patients started with a dose of $60 \mathrm{mg}$ daily; $74 \%$, with a dose of $30 \mathrm{mg}$ daily; and $3 \%$, with a dose of $15 \mathrm{mg}$ daily. In the rivaroxaban group, $43 \%$ of the patients received an initial dose of $15 \mathrm{mg}$ daily, while only $50 \%$ percent received $30 \mathrm{mg}$ daily, which is regarded as the recommended initial dose of rivaroxaban. In the apixaban group, $12 \%$ received an initial dose of $20 \mathrm{mg}$ daily, $73 \%$ received an initial dose of $10 \mathrm{mg}$ daily, and $15 \%$ received a reduced initial dose of $5 \mathrm{mg}$ daily.

Safety. During the study period, 56 patients (17.9\%) discontinued the oral anticoagulant administration or needed drug change to other DOACs (Table II). The major reason 
Table I. Characteristics of the 312 patients with active cancer and VTE.

\begin{tabular}{|c|c|c|c|}
\hline Variable & $\begin{array}{l}\text { Edoxaban } \\
(\mathrm{n}=205)\end{array}$ & $\begin{array}{c}\text { Rivaroxaban } \\
\quad(\mathrm{n}=74)\end{array}$ & $\begin{array}{l}\text { Apixaban } \\
(\mathrm{n}=33)\end{array}$ \\
\hline $\begin{array}{l}\text { Age (years), } \\
\text { median (range) }\end{array}$ & $69(35-84)$ & $63(45-79)$ & $68(61-84)$ \\
\hline $\begin{array}{l}\text { Gender } \\
\text { (male/female), n (\%) }\end{array}$ & $84 / 121(41 / 59)$ & $39 / 35(53 / 47)$ & $14 / 19(42 / 58)$ \\
\hline $\begin{array}{l}\text { Creatinine clearance } \\
(\mathrm{ml} / \mathrm{min}), \text { mean }(\mathrm{SD})\end{array}$ & $78.9(32.7)$ & $86.5(30.8)$ & $70.8(26.0)$ \\
\hline \multicolumn{4}{|l|}{$\begin{array}{l}\text { Primary site of } \\
\text { cancer, } \mathrm{n}(\%)\end{array}$} \\
\hline Lung & $47(23)$ & $8(11)$ & $8(24)$ \\
\hline Stomach & $22(11)$ & $15(20)$ & $5(15)$ \\
\hline Colon and rectum & $23(11)$ & $12(16)$ & $3(9)$ \\
\hline Ovary & $20(10)$ & $9(12)$ & $4(12)$ \\
\hline Hemopoietic & $23(11)$ & $6(8)$ & $4(12)$ \\
\hline Urothelial & $12(6)$ & $5(7)$ & $1(3)$ \\
\hline Breast & $13(6)$ & $3(4)$ & $1(3)$ \\
\hline Uterus & $13(6)$ & $2(3)$ & $0(0)$ \\
\hline Pancreas & $8(4)$ & $4(5)$ & $2(6)$ \\
\hline Esophageal & $5(2)$ & $3(4)$ & $1(3)$ \\
\hline Cervix & $5(2)$ & $1(1)$ & $2(6)$ \\
\hline Biliary tract & $4(2)$ & $1(1)$ & $2(6)$ \\
\hline Kidney & $6(3)$ & $0(0)$ & $0(0)$ \\
\hline Othera & $6(3)$ & $8(11)$ & $0(0)$ \\
\hline \multicolumn{4}{|l|}{ Starting dose, mg/day } \\
\hline 60 & $48(23)$ & & \\
\hline 30 & $151(74)$ & $37(50)$ & $0(0)$ \\
\hline 20 & $0(0)$ & $2(3)$ & $4(12)$ \\
\hline 15 & $6(3)$ & $32(55)$ & $0(0)$ \\
\hline 10 & $0(0)$ & $2(5)$ & $24(73)$ \\
\hline 5 & $0(0)$ & $0(0)$ & $5(15)$ \\
\hline Unknown & $0(0)$ & $1(3)$ & $0(0)$ \\
\hline
\end{tabular}

VTE: Venous thromboembolism; SD: standard deviation. a Other cancer types in the edoxaban group included prostate, head, vagina, and testes, while the other cancer types in the rivaroxaban group included head, teratoma, mesothelioma, liver, and prostate. Seven patients had two cancer types simultaneously.

for discontinuation was bleeding $(\mathrm{n}=50)$. In the edoxaban group, 31 patients $(15.1 \%)$ discontinued the drug due to gastrointestinal bleeding $(n=8)$, hemoptysis $(n=6)$, hematuria $(n=5)$, and epistaxis $(n=4)$. In the rivaroxaban group, 12 patients $(16.2 \%)$ discontinued the drug due to gastrointestinal bleeding $(n=3)$, hematuria $(n=3)$, epistaxis $(n=2)$, and anemia $(n=2)$. In the apixaban group, nine patients $(27.3 \%)$ discontinued the drug due to gastrointestinal bleeding $(n=2)$, hematuria $(n=2)$, anemia $(n=2)$, epistaxis $(n=1)$, hemorrhagic pleural effusion $(n=1)$, and liver enzyme elevation $(n=1)$. Major bleeding occurred in 18 patients: 11 in the edoxaban group $(5.4 \%)$, four in the rivaroxaban group $(5.4 \%)$, and three in the apixaban group $(9.1 \%)$.

We also compared the relationship between renal function and bleeding rate. Figure 1 shows the comparison of renal function in patients with or without bleeding. In the
Table II. Reasons for drug discontinuation ( $n=312)$.

\begin{tabular}{lccc}
\hline Variable & $\begin{array}{c}\text { Edoxaban } \\
(\mathrm{n}=205)\end{array}$ & $\begin{array}{c}\text { Rivaroxaban } \\
(\mathrm{n}=74)\end{array}$ & $\begin{array}{c}\text { Apixaban } \\
(\mathrm{n}=33)\end{array}$ \\
\hline Discontinuation, n (\%) & $35(17)$ & $12(16)$ & $9(27)$ \\
Gastrointestinal bleeding & $8(4)$ & $3(4)$ & $2(6)$ \\
Hematuria & $5(2)$ & $3(4)$ & $2(6)$ \\
Epistaxis & $4(2)$ & $2(3)$ & $1(3)$ \\
Anemia & $2(1)$ & $2(3)$ & $2(6)$ \\
Hemoptysis & $6(3)$ & $0(0)$ & $0(0)$ \\
Bleeding from other lesions & $6(3)$ & $1(1)$ & $1(3)$ \\
Rash & $2(1)$ & $1(1)$ & $0(0)$ \\
Edema & $1(0.5)$ & $0(0)$ & $0(0)$ \\
Fever & $1(0.5)$ & $0(0)$ & $0(0)$ \\
Liver enzyme elevation & $0(0)$ & $0(0)$ & $1(3)$ \\
\hline
\end{tabular}

edoxaban group, the mean (standard deviation, SD) Ccr of patients with bleeding $(\mathrm{n}=31)$ was $75.2(28.8) \mathrm{ml} / \mathrm{min}$ and of patients without bleeding $(\mathrm{n}=174)$ was $79.6(33.4) \mathrm{ml} / \mathrm{min}$ $(p=0.48)$. In the rivaroxaban group, the mean (SD) Ccr of patients with bleeding $(\mathrm{n}=11)$ was $73.8(28.0) \mathrm{ml} / \mathrm{min}$ and that of patients without bleeding $(n=63)$ was 88.7 (30.9) $\mathrm{ml} / \mathrm{min}(p=0.14)$. In the apixaban group, the mean (SD) $\mathrm{Ccr}$ of patients with bleeding $(\mathrm{n}=8)$ was $58.9(24.8) \mathrm{ml} / \mathrm{min}$ and that of patients without bleeding $(n=25)$ was 74.7 (25.7) $\mathrm{ml} / \mathrm{min}(p=0.14)$.

Patients in each group were stratified using the renal function and bleeding rate (Figure 2). In the edoxaban group, $14 \%$ of patients with a $\mathrm{Ccr}<50 \mathrm{ml} / \mathrm{min}, 18 \%$ of patients with a $\leq 50 \mathrm{Ccr}<80 \mathrm{ml} / \mathrm{min}$, and $13 \%$ of patients with a $\mathrm{Ccr} \geq 80$ $\mathrm{ml} / \mathrm{min}$ experienced bleeding. In the rivaroxaban group, $33 \%$ of patients with a $\mathrm{Ccr}<50 \mathrm{ml} / \mathrm{min}, 17 \%$ of patients with a $\leq 50 \mathrm{Ccr}<80 \mathrm{ml} / \mathrm{min}$, and $8 \%$ of patients with a Ccr $\geq 80$ $\mathrm{ml} / \mathrm{min}$ experienced bleeding. In the apixaban group, $50 \%$ of patients with a $\mathrm{Ccr}<50 \mathrm{ml} / \mathrm{min}, 15 \%$ of patients with a $\leq 50$ $\mathrm{Ccr}<80 \mathrm{ml} / \mathrm{min}$, and $17 \%$ of patients with a Ccr $\geq 80 \mathrm{ml} / \mathrm{min}$ experienced bleeding.

Efficacy. We were able to evaluate the efficacy of the DOACs in 167 patients; $144(86.2 \%)$ patients showed reduction or resolution of VTE. In the edoxaban group, thrombosis reduced or resolved in 88 of the 106 evaluated patients (83.0\%). PE resolved in 19 and reduced in 8 of the 29 patients (93.1\%). In the rivaroxaban group, thrombosis was reduced or resolved in 44 of the 48 evaluated patients $(91.7 \%)$. PE resolved in 15 and reduced in 2 of the 19 patients $(89.5 \%)$. In the apixaban group, thrombosis showed an improvement in 12 of the 13 evaluated patients $(92.3 \%)$ who were evaluated. PE resolved in two patients $(100 \%)$ (Table III).

Changes in the D-dimer levels from DOAC initiation to 1 month later were also assessed in this study (Figure 3). The mean value of the D-dimer levels in the edoxaban group 
a

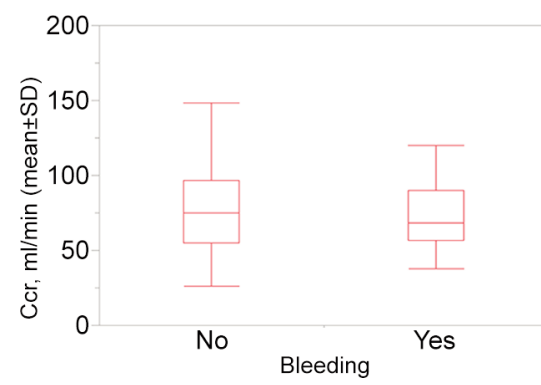

b

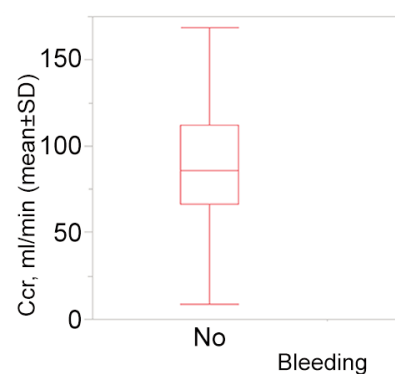

C

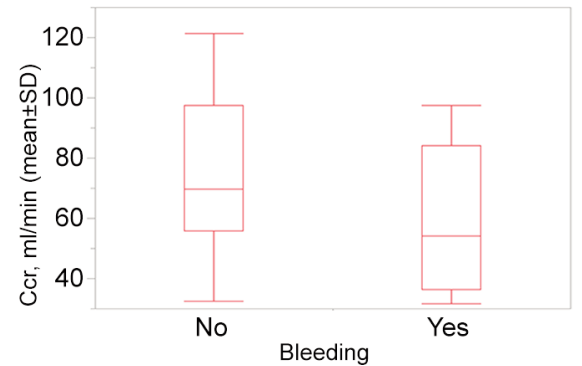

Figure 1. Renal function in patients with or without clinically relevant and major bleeding. (A) Edoxaban ( $n=205),(B)$ Rivaroxaban ( $n=74)$, (C) Apixaban (n=33). Ccr: Creatinine clearance rate; pts: patients; SD: standard deviation.
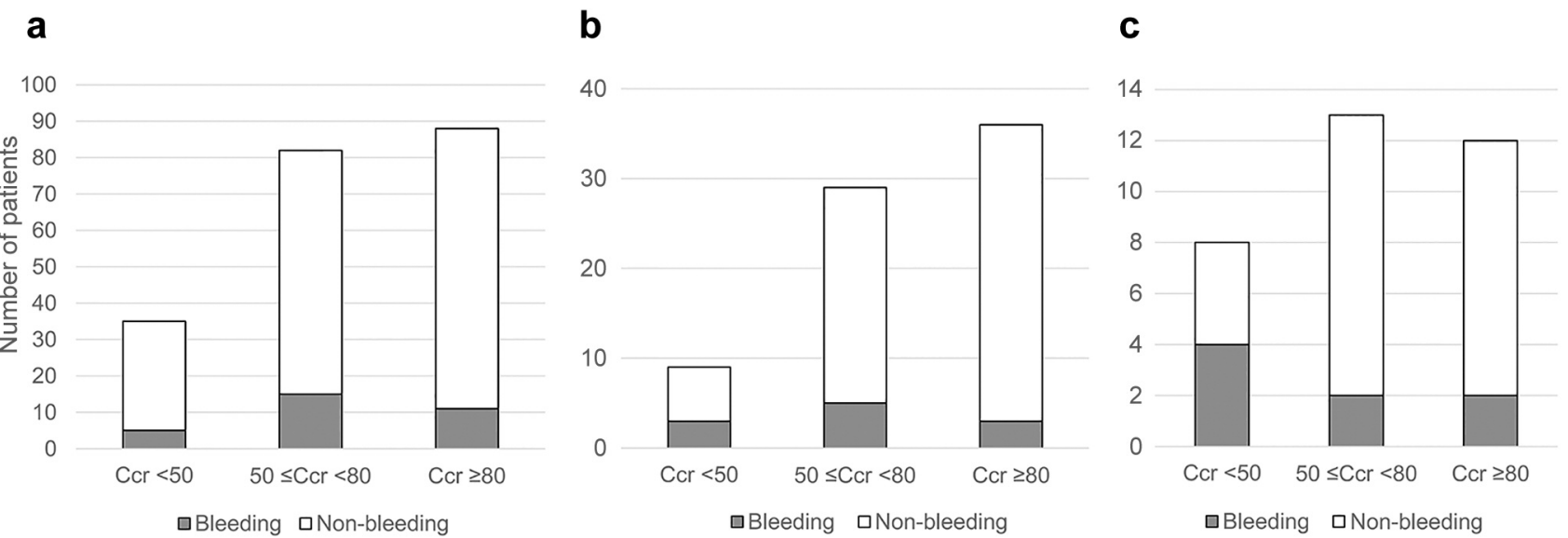

Figure 2. Clinically relevant and major bleeding classified based on renal function. (A) Edoxaban ( $n=205)$, (B) Rivaroxaban ( $n=74)$, (C) Apixaban (n=33). Ccr: Creatinine clearance rate; ns: not significant.

decreased from 11.5 to $6.9 \mu \mathrm{g} / \mathrm{ml}(p=0.04)$, that in the rivaroxaban group decreased from 13.4 to $4.9 \mu \mathrm{g} / \mathrm{ml}$ $(p=0.0004)$ and that in the apixaban group decreased from 17.2 to $3.3 \mu \mathrm{g} / \mathrm{ml}(p=0.019)$ after 1 month of DOAC administration.

\section{Discussion}

We found that DOACs for cancer-associated VTE appear to be as safe and effective as conventional anticoagulation therapy. The present study is clinically significant because it describes the actual experience of managing VTE in patients with active cancer.

From the safety point, we reviewed the rate of major bleeding reported in each clinical trial. In the Hokusai VTE Cancer study, major bleeding occurred in $6.9 \%$ patients when using edoxaban for cancer VTE compared with $4.0 \%$ in the dalteparin group (95\% CI=0.1-5.6). Rivaroxaban has a reduced rate of major bleeding events compared to the combination therapy of heparin and warfarin in the general population (15), as well as in patients with cancer, according
Table III. Effectiveness of DOACs ( $n=167)$.

\begin{tabular}{lccc}
\hline Variable & $\begin{array}{c}\text { Edoxaban } \\
\mathrm{n}(\%)\end{array}$ & $\begin{array}{c}\text { Rivaroxaban } \\
\mathrm{n}(\%)\end{array}$ & $\begin{array}{c}\text { Apixaban } \\
\mathrm{n}(\%)\end{array}$ \\
\hline Patients with DVT and/or PE & 106 & 48 & 13 \\
Improved or normalized & $88(83)$ & $44(92)$ & $12(92)$ \\
Unchanged & $11(10)$ & $4(8)$ & $0(0)$ \\
Deteriorated & $7(7)$ & $0(0)$ & $1(8)$ \\
Patients with PE & 29 & 19 & 2 \\
Improved or normalized & $27(93)$ & $17(89)$ & $2(100)$ \\
Normalized & $19(66)$ & $15(79)$ & $2(100)$ \\
Unchanged & $1(3)$ & $1(5)$ & $0(0)$ \\
Deteriorated & $1(3)$ & $1(5)$ & $0(0)$ \\
\hline
\end{tabular}

DOACS: Direct oral anticoagulants; DVT: deep vein thrombosis; PE: pulmonary embolism.

to a subgroup analysis (16). The J-EINSTEIN DVT/PE study reported the bleeding rates and reduction or resolution rate of DVT/PE in Japanese patients (17). The SELECT-D study 

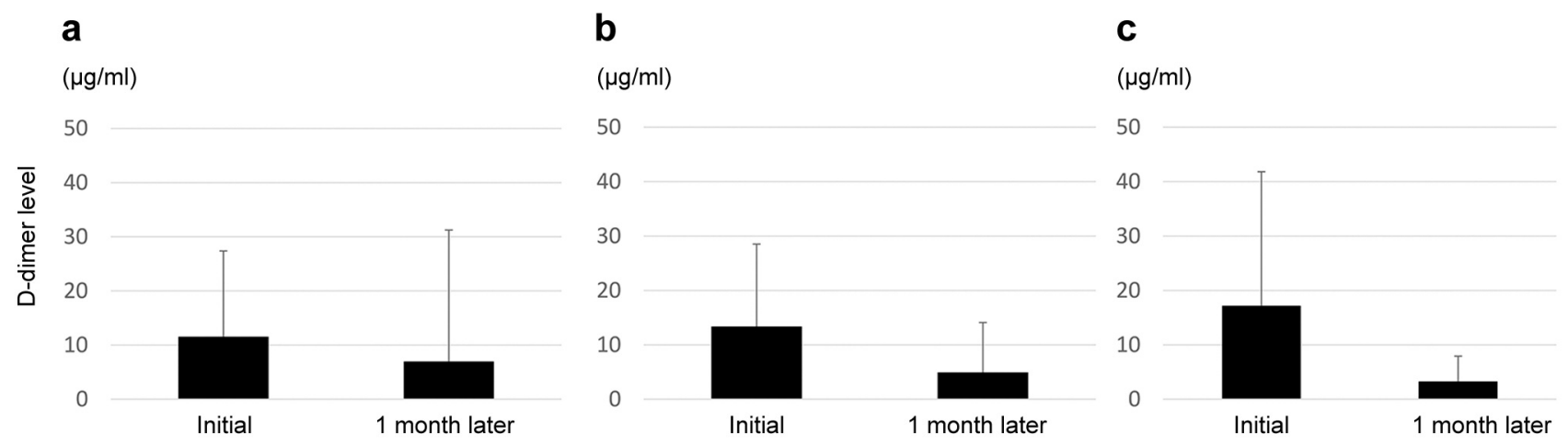

Figure 3. D-dimer levels at direct oral anticoagulant (DOAC) initiation and 1 month after DOAC initiation. (A) Edoxaban ( $n=205)$, (B) Rivaroxaban $(n=74)$, (C) Apixaban (n=33).

reported major bleeding in $5.4 \%$ patients in the rivaroxaban group compared with $3.0 \%$ patients in the dalteparin group (18). Apixaban use for cancer-associated VTE has recently been published and no major bleeding was observed in the apixaban group (19). However, a systematic review of the use of DOACs using meta-analysis for the treatment of cancer-associated VTE found that DOACs may increase major bleeding (20). In the current analysis, major bleeding, as defined by the International Society on Thrombosis and Hemostasis, was observed in $11(5.4 \%)$ in the edoxaban group, a result similar to that of the Hokusai VTE Cancer study $(6.9 \%)$; four $(5.4 \%)$ were in the rivaroxaban group, a result similar to that of the SELECT-D study (5.4\%); and three $(9.1 \%)$ were in the apixaban group. Although apixaban was administered to a small number of patients in our study, we should be careful in making the direct comparison with clinical trial. Considering that this study collected the actual experience in Japan, we can confidently say that DOACS can also be used safely in patients with cancer.

The next concern is whether DOACs are effective. We evaluated the efficacy by imaging the changes in the thrombus and assessing D-dimer levels. In our study, thrombosis reduced or resolved in 144 out of 167 evaluable patients $(86 \%)$ and PE resolved in 46 out of 50 patients (92\%). In the J-EINSTEIN DVT/PE study, despite the small number of cancer patients at high risk of DVT and bleeding, the results were similar to those of our study (17). The AMPLIFY study also showed similar results (21). In our study, because the treatment period at the time of imaging evaluation differed significantly, the interpretation is limited. Furthermore, clinical trials on both rivaroxaban and apixaban have confirmed the usefulness of initial treatment using a single-drug approach. In our study, rivaroxaban was administered as a single drug in 72 of 74 patients and apixaban in 30 of 33 patients. Edoxaban was also administered as a single-drug approach in 184 of 205 patients. This suggests that VTE in cancer patients may be easier to manage with DOACs, with similar effectiveness and safety, than with the conventional anti-coagulant therapies. D-dimers were surveyed at DOAC initiation and 1 month later, and patients in all the groups exhibited reduced D-dimer levels 1 month after DOAC initiation. This finding also supports the effectiveness of DOACs in reducing the risk of VTE recurrence.

The other difference regarding these three DOACs is that edoxaban and apixaban require dose modification according to the patient's renal function, whereas rivaroxaban does not. However, because rivaroxaban clearance decreases with increasing renal impairment (22), rivaroxaban actually requires dose modification when administered for atrial fibrillation and in the interest of the safety of patients with reduced renal function. In fact, the rate of bleeding was significantly different between patients in the rivaroxaban group with a $\mathrm{Ccr}<50$ $\mathrm{ml} / \mathrm{min}$ and those with a $\mathrm{Ccr}<80 \mathrm{ml} / \mathrm{min}$. Nevertheless, it is unclear whether this result is clinically significant because of the small sample size. This aspect should be studied in the future to ensure the proper and safe management of VTE in patients with reduced renal function.

Limitations of our study include that it was conducted retrospectively at a single institution, that the number of included patients varies among treatments with the three drugs and that the efficacy of the DOACs was not evaluated in all patients.

\section{Conclusion}

In conclusion, our findings suggest that DOACs may be as safe and effective as the conventional anticoagulation therapy for VTE treatment. Further studies are needed to clarify the safety and effectiveness of other DOACs.

\section{Conflicts of Interest}

Hironaga Satake has received research funding from Ono Pharmaceutical Co. Ltd., Daiichi Sankyo, Taiho Pharmaceutical Co., Ltd., Takeda Pharmaceutical Co., Ltd. and Sanofi, honoraria from 
Bayer Co., Ltd., Bristol-Myers Squibb Co., Ltd., Chugai Pharmaceutical Co., Ltd., Daiichi Sankyo Co., Ltd., Eli Lilly Japan Co., Ltd., Merck Bio Pharma Co., Ltd., MSD Co., Ltd., Ono Pharmaceutical Co., Ltd., Sanofi Co., Ltd., Taiho Pharmaceutical Co., Ltd., Takeda Co., Ltd. and Yakult Honsha Co., Ltd.

Hisateru Yasui has received research funding from MSD, Daiichi Sankyo, and Ono Pharmaceutical, honoraria from Taiho Pharmaceutical, Chugai Pharma, Bristol-Myers Squibb Japan, Daiichi Sankyo, TERUMO, Eli Lilly Japan, Merck Biopharma, and Yakult Honsha. All remaining authors have declared no conflict of interest.

\section{Author's Contributions}

Conceptualization: H.S. Data acquisition: M.O., H.S., Y.A., T.O., M.H., H.Y. Manuscript preparation: M.O., H.S. Manuscript editing: M.O., H.S. Manuscript review: All Authors.

\section{Acknowledgements}

We would like to thank the patients and families who participated in this study.

\section{References}

1 Verso M, Agnelli G and Prandoni P: Pros and cons of new oral anticoagulants in the treatment of venous thromboembolism in patients with cancer. Intern Emerg Med 10(6): 651-656, 2015. PMID: 25840679. DOI: 10.1007/s11739-015-1233-5

2 Cronin-Fenton DP, Søndergaard F, Pedersen LA, Fryzek JP, Cetin K, Acquavella J, Baron JA and Sørensen HT: Hospitalisation for venous thromboembolism in cancer patients and the general population: a population-based cohort study in Denmark, 1997-2006. Br J Cancer 103(7): 947-953, 2010. PMID: 20842120. DOI: 10.1038/sj.bjc.6605883

3 Heit JA, Silverstein MD, Mohr DN, Petterson TM, O'Fallon WM and Melton LJ 3rd: Risk factors for deep vein thrombosis and pulmonary embolism: a population-based case-control study. Arch Intern Med 160(6): 809-815, 2000. PMID: 10737280. DOI: 10.1001/archinte.160.6.809

4 Nakamura M, Miyata T, Ozeki Y, Takayama M, Komori K, Yamada N, Origasa H, Satokawa H, Maeda H, Tanabe N, Unno N, Shibuya T, Tanemoto K, Kondo K and Kojima T: Current venous thromboembolism management and outcomes in Japan. Circ J 78(3): 708-717, 2014. PMID: 24401573. DOI: 10.1253/ circj.cj-13-0886

5 Prandoni P, Lensing AW, Piccioli A, Bernardi E, Simioni P, Girolami B, Marchiori A, Sabbion P, Prins MH, Noventa F and Girolami A: Recurrent venous thromboembolism and bleeding complications during anticoagulant treatment in patients with cancer and venous thrombosis. Blood 100(10): 3484-3488, 2002. PMID: 12393647. DOI: 10.1182/blood-2002-01-0108

6 Khorana AA: Venous thromboembolism and prognosis in cancer. Thromb Res 125(6): 490-493, 2010. PMID: 20097409. DOI: 10.1016/j.thromres.2009.12.023

7 Sørensen HT, Mellemkjaer L, Olsen JH and Baron JA: Prognosis of cancers associated with venous thromboembolism. N Engl J Med 343(25): 1846-1850, 2000. PMID: 11117976. DOI: 10.1056/NEJM200012213432504
8 Farge D, Debourdeau P, Beckers M, Baglin C, Bauersachs RM, Brenner B, Brilhante D, Falanga A, Gerotzafias GT, Haim N, Kakkar AK, Khorana AA, Lecumberri R, Mandala M, Marty M, Monreal M, Mousa SA, Noble S, Pabinger I, Prandoni P, Prins MH, Qari MH, Streiff MB, Syrigos K, Bounameaux H and Büller HR: International clinical practice guidelines for the treatment and prophylaxis of venous thromboembolism in patients with cancer. J Thromb Haemost 11(1): 56-70, 2013. PMID: 23217107. DOI: 10.1111/jth.12070

9 Kearon C, Akl EA, Ornelas J, Blaivas A, Jimenez D, Bounameaux H, Huisman M, King CS, Morris TA, Sood N, Stevens SM, Vintch JRE, Wells P, Woller SC and Moores L: Antithrombotic therapy for VTE disease: CHEST guideline and expert panel report. Chest 149(2): 315-352, 2016. PMID: 26867832. DOI: 10.1016/j.chest.2015.11.026

10 Key NS, Khorana AA, Kuderer NM, Bohlke K, Lee AYY, Arcelus JI, Wong SL, Balaban EP, Flowers CR, Francis CW, Gates LE, Kakkar AK, Levine MN, Liebman HA, Tempero MA, Lyman GH and Falanga A: Venous thromboembolism prophylaxis and treatment in patients with cancer: ASCO clinical practice guideline update. J Clin Oncol 38(5): 496-520, 2020. PMID: 31381464. DOI: 10.1200/JCO.19.01461

11 Yamamura K, Beppu T, Kinoshita K, Oda E, Sato N, Yuki H, Motohara T, Miyamoto H, Kawaguchi H, Komohara Y and Akahoshi S: Hepatocellular carcinoma with extensive cancerassociated thrombosis successfully treated with liver resection and direct oral anticoagulant: a case report. Anticancer Res 40(11): 6465-6471, 2020. PMID: 33109585. DOI: 10.21873/ anticanres. 14668

12 Carrier M, Abou-Nassar K, Mallick R, Tagalakis V, Shivakumar S, Schattner A, Kuruvilla P, Hill D, Spadafora S, Marquis K, Trinkaus M, Tomiak A, Lee AYY, Gross PL, Lazo-Langner A, El-Maraghi R, Goss G, Le Gal G, Stewart D, Ramsay T, Rodger M, Witham D, Wells PS and AVERT Investigators: Apixaban to prevent venous thromboembolism in patients with cancer. $\mathrm{N}$ Engl J Med 380(8): 711-719, 2019. PMID: 30511879. DOI: 10.1056/NEJMoa1814468

13 Raskob GE, van Es N, Verhamme P, Carrier M, Di Nisio M, Garcia D, Grosso MA, Kakkar AK, Kovacs MJ, Mercuri MF, Meyer G, Segers A, Shi M, Wang TF, Yeo E, Zhang G, Zwicker JI, Weitz JI, Büller HR and Hokusai VTE Cancer Investigators: Edoxaban for the treatment of cancer-associated venous thromboembolism. N Engl J Med 378(7): 615-624, 2018. PMID: 29231094. DOI: 10.1056/NEJMoa1711948

14 Schulman S, Angerås U, Bergqvist D, Eriksson B, Lassen MR, Fisher W and Subcommittee on Control of Anticoagulation of the Scientific and Standardization Committee of the International Society on Thrombosis and Haemostasis: Definition of major bleeding in clinical investigations of antihemostatic medicinal products in surgical patients. J Thromb Haemost 8(1): 202-204, 2010. PMID: 19878532. DOI: 10.1111/j.1538-7836.2009.03678.x

15 Prins MH, Lensing AW, Bauersachs R, van Bellen B, Bounameaux H, Brighton TA, Cohen AT, Davidson BL, Decousus H, Raskob GE, Berkowitz SD, Wells PS and EINSTEIN Investigators: Oral rivaroxaban versus standard therapy for the treatment of symptomatic venous thromboembolism: a pooled analysis of the EINSTEIN-DVT and PE randomized studies. Thromb J 11(1): 21, 2013. PMID: 24053656. DOI: 10.1186/1477-9560-11-21

16 Prins MH, Lensing AW, Brighton TA, Lyons RM, Rehm J, Trajanovic M, Davidson BL, Beyer-Westendorf J, Pap ÁF, 
Berkowitz SD, Cohen AT, Kovacs MJ, Wells PS and Prandoni $\mathrm{P}$ : Oral rivaroxaban versus enoxaparin with vitamin $\mathrm{K}$ antagonist for the treatment of symptomatic venous thromboembolism in patients with cancer (EINSTEIN-DVT and EINSTEIN-PE): a pooled subgroup analysis of two randomised controlled trials. Lancet Haematol 1(1): e37-e46, 2014. PMID: 27030066. DOI: $10.1016 /$ S2352-3026(14)70018-3

17 Yamada N, Hirayama A, Maeda H, Sakagami S, Shikata H, Prins MH, Lensing AW, Kato M, Onuma J, Miyamoto Y, Iekushi K and Kajikawa M: Oral rivaroxaban for Japanese patients with symptomatic venous thromboembolism - the J-EINSTEIN DVT and PE program. Thromb J 13: 2, 2015. PMID: 25717286. DOI: 10.1186/s12959-015-0035-3

18 Young AM, Marshall A, Thirlwall J, Chapman O, Lokare A, Hill C, Hale D, Dunn JA, Lyman GH, Hutchinson C, MacCallum P, Kakkar A, Hobbs FDR, Petrou S, Dale J, Poole CJ, Maraveyas $\mathrm{A}$ and Levine M: Comparison of an oral factor Xa inhibitor with low molecular weight heparin in patients with cancer with venous thromboembolism: Results of a randomized trial (SELECT-D). J Clin Oncol 36(20): 2017-2023, 2018. PMID: 29746227. DOI: $10.1200 /$ JCO.2018.78.8034

19 McBane RD 2nd, Wysokinski WE, Le-Rademacher JG, Zemla T, Ashrani A, Tafur A, Perepu U, Anderson D, Gundabolu K, Kuzma C, Perez Botero J, Leon Ferre RA, Henkin S, Lenz CJ, Houghton DE, Vishnu P and Loprinzi CL: Apixaban and dalteparin in active malignancy-associated venous thromboembolism: The ADAM VTE trial. J Thromb Haemost 18(2): 411-421, 2020. PMID: 31630479. DOI: $10.1111 /$ jth. 14662
20 Fuentes HE, McBane RD 2nd, Wysokinski WE, Tafur AJ, Loprinzi CL, Murad MH and Riaz IB: Direct oral factor Xa inhibitors for the treatment of acute cancer-associated venous thromboembolism: a systematic review and network metaanalysis. Mayo Clin Proc 94(12): 2444-2454, 2019. PMID: 31685262. DOI: 10.1016/j.mayocp.2019.05.035

21 Agnelli G, Buller HR, Cohen A, Curto M, Gallus AS, Johnson M, Masiukiewicz U, Pak R, Thompson J, Raskob GE, Weitz JI and AMPLIFY Investigators: Oral apixaban for the treatment of acute venous thromboembolism. N Engl J Med 369(9): 799-808, 2013. PMID: 23808982. DOI: 10.1056/NEJMoa1302507

22 Kubitza D, Becka M, Mueck W, Halabi A, Maatouk H, Klause N, Lufft V, Wand DD, Philipp T and Bruck H: Effects of renal impairment on the pharmacokinetics, pharmacodynamics and safety of rivaroxaban, an oral, direct Factor Xa inhibitor. Br J Clin Pharmacol 70(5): 703-712, 2010. PMID: 21039764. DOI: $10.1111 / \mathrm{j} .1365-2125.2010 .03753 . \mathrm{x}$

Received May 31, 2021

Revised June 25, 2021

Accepted July 8, 2021 